\title{
Strategies for Mutation Discovery in Retinitis Pigmen- tosa: Transition to the Next Generation
}

\author{
Chang Ki Yoon and Hyeong Gon Yu*
}

Department of Ophthalmology, Seoul National University College of Medicine, Seoul, Korea

\begin{abstract}
Retinitis pigmentosa (RP) is the most common hereditary retinal disorder and is characterized by progressive retinal degeneration and decline in vision. RP comprises a heterogeneous group of disorders caused by various genetic variants. Since the first discovery of the causal mutation in the $R H O$ gene using positional cloning, numerous mutations have been detected in more than 60 loci and 50 genes. However, causal genes have not been discovered in about $50 \%$ of cases. We attempt here to review the strategies to identify causal alleles of retinitis pigmentosa. These include conventional methods as well as state-of-the-art technologies based on next-generation sequencing.
\end{abstract}

Key words: Retinitis pigmentosa, RHOgene, Next-generation sequencing

\section{Introduction}

Retinitis pigmentosa (RP, OMIM 268000) is a group of hereditary retinal diseases characterized by progressive loss of rod and cone photoreceptor cells. It is relatively common, and the worldwide incidence is 1 in 4,000 people worldwide. Patients usually present with night blindness and complain about progressive constriction of their visual field. Central vision is eventually affected and then declines. Clinical features vary dramatically among individuals.

Although RP usually affects the eye alone (nonsyndromic), approximately 20-30\% of RP cases is also related with other diseases not involving the eye (syndromic). Inheritance patterns include autosomal recessive (20\%), autosomal dominant (10-20\%), or an X-linked recessive pattern (10\%). Up to 40\% of cases are defined as simplex RP, which has no family history. Most cases of simplex RP may be caused by autosomal recessive inheritance. If sporadic RP is considered autosomal recessive, the approximate proportions change as follows: $30-40 \%$ autosomal dominant, $50-60 \%$ auto- somal recessive, and 5-15\% X-linked.' Further, rare forms of nonMendelian inheritance occur, such as mitochondrial or digenic inheritance.

Since the original discovery in 1990 that a mutation in the $\mathrm{RHO}$ gene encoding rhodopsin caused RP in one family, more than 60 loci and 50 genes have been identified as sites of causative mutations. ${ }^{2)}$ The identification of the causative mutation enables molecular diagnosis, carrier testing, and facilitates disease management and family counseling. Eventually, the causative mutation can serve as a target of therapy.

Since the technical breakthroughs for performing genetic analysis such as Sanger sequencing or polymerase chain reaction (PCR), further remarkable advances have been made at a rapid rate. For example, because of its lower cost, high-throughput sequencing is now available to a wide range of researchers. Despite recent advances in identifying the genetic basis of $\mathrm{RP}$, several difficult hurdles must be overcome to better definition of its molecular basis. These include the large number of genes

Received: 23 May 2013, Revised: 7 June 2013, Accepted: 12 June 2013, Published: 30 June 2013

${ }^{*}$ Corresponding author: Hyeong Gon Yu, M.D., Ph.D.

Department of Ophthalmology, Seoul National University College of Medicine, 101 Daehang-no, Jongno-gu, Seoul 110-744, Korea

Tel: +82-2-2072-2438, FAX: +82-2-741-3187, E-mail: hgonyu@snu.ac.kr

(c) This is an open-access article distributed under the terms of the Creative Commons Attribution Non-Commercial License (http://creativecommons.org/licenses/by-nc/3.0/) which permits unrestricted non-commercial use, distribution, and reproduction in any medium, provided the original work is properly cited.

(c) Copyright 2013 by the Korean Society of Medical Genetics 
and mutations identified as well as non-Mendelian inheritance patterns such as digenic inheritance or incomplete penetrance. For example, different mutations in the same gene can generate different phenotypes, and the same mutation in different individuals may cause distinctly different symptoms. Moreover, genetic diversity among populations differing in ethnicity and geographical location is also problematic. ${ }^{3,4)}$ Therefore, to identify the mutations that cause RP, comprehensive approaches and meticulous validation are required.

In the present review, we attempt to describe the major methodologies available for discovering genetic abnormalities in retinitis pigmentosa with particular emphasis on next-generation sequencing-based exomesequencing.

\section{Positional Cloning}

A disease gene that is inherited in Mendelian fashion can be identified knowing nothing but its approximate chromosomal location. The first step of positional cloning is defining the candidate region and identifying all the genes that reside within. The success of positional cloning depends upon whether the disease is closely related to known genetic markers, which is difficult to predict. Targeted genes are prioritized for screening for mutations and then verifying their presence in the affected patient.

\section{Genetic mapping by linkage analysis}

Linkage analysis was first applied in 1985 for identifying the gene responsible for $X$-linked chronic granulomatous disease. ${ }^{5}$ The first discovery of the mutation that causes autosomal dominant RP (RhoPro23His in RHO) was reported by Dryja et al. ${ }^{6}$ and was based on the finding that a large pedigree of autosomal dominant $\mathrm{RP}$ is linked to an anonymous polymorphic sequence from the long arm of chromosome 3. Moreover, the gene encoding rhodopsin is also assigned to that region. Peripherin/RDS, RP1, and PRPF3 mutations were also identified as causative for dominant RP using linkage mapping. ${ }^{6-8)}$ Linkage analysis is a powerful tool for identifying Mendelian mutations, because it is relatively easy to perform. However, its application is limited to affected large families.

\section{Genetic positioning by homozygosity mapping}

Homozygosity mapping is an efficient strategy to identify mutations associated with autosomal recessive traits in consanguineous families. This has enabled mapping of many recessive diseases, which would have been otherwise difficult in the absence of adequate numbers of affected families with multiple affected members. ${ }^{9)}$ Several rare causal genes like C2orf71, C9ORF37, FAMA161A, IMPG2, and RBP3 are identified using homozygosity mapping. ${ }^{10-15)}$

\section{Candidate gene approach}

The candidate gene approach involves targeting a gene based on biochemical knowledge, such as the function of or tissue-specific expression of its encoded protein. The most promising genes are prioritized and analyzed to find genetic variants. Computer analysis has been employed to search for and classify candidate genes using public domain databases. ${ }^{16)}$

The direct confirmation of genetic alteration in candidate gene may be a sequencing. We will discuss the sequencing in detail at latter part of this text. Before that, several representative screening tools used to detect mutations in candidate regions are explained here.

\section{Microarrays}

A microarray is a device in which beads or wells composed of thousands of unique DNA oligonucleotide probes are arrayed.

The Arrayed Primer Extension microarray (APEX) is oriented toward diagnosis and involves hybridization of a PCR-amplified mutant target DNA to an immobilized primer derived from a region adjacent to the loci of presumptive variants. After extending a single base labeled with either of four terminating dideoxynucleotide triphosphates (ddNTPs), the identities of newly incorporated nucleotides are determined. ${ }^{1718)}$ Commercially available RP diagnosis kits using APEX technology have been introduced. ${ }^{19-21)}$

There are two representative microarray platforms for genomewide association study (GWAS). The Affymetrix single-nucleotide polymorphism (SNP) array uses approximately 25 base-long oligonucleotides harboring all possible alleles at the polymorphic site. If there is a DNA matched with the probes, all SNPs can be identified. In contrast, the Illumina SNP array determines the polymorphism by a single base extension to the locus-specific primer. ${ }^{22,23}$ Both SNP arrays are currently used in RP mutation screening ${ }_{1}{ }^{24-26)}$ and Illumina SNP genotyping arrays have been utilized for homozygosityscreening of patients with $\mathrm{RP}^{27,28)}$

We previously screened a $336 \mathrm{RP}$ cohort using microarrays. ${ }^{24)}$ We used the Illumina SNP array platform (GoldenGate Genotyping Assay) that included about 95 known mutations from 28 genes. 
Ten RP-related mutations in five RP genes were identified in 26 of 336 patients (7.7\%). Microarray offers a rapid screening, however the main shortcoming, as was the case for this study, is that it only detects known mutations. Therefore, customizable SNP array platforms were developed, and a novel mutation was identified using customized microarray-based resequencing. ${ }^{26)}$ In addition the detection rate was relatively low, less that $15 \%$, for practical genetic counseling. ${ }^{24,26,29)}$

\section{High resolution melting (HRM) analysis}

HRM analysis determines the melting pattern of double-stranded DNA. HRM starts with PCR amplification of the target region using an intercalating fluorescent dye. As the temperature of the reaction mixture increases, the two strands of the amplicon DNA are separated (melted) and the fluorescent dye is released. The melting curve is obtained by measuring the fluorescence of the dye and the temperature. All genetic variants, including substitutions, inversions, and deletions, even at the level of a single nucleotide, are detected by comparing the melting curves between the test sample and a wild-type reference. In addition to its sensitivity, HRM is relatively inexpensive, because reaction and analysis are performed in the same device using a simple process. ${ }^{30,311}$ However, deletions of multiple exons may not be detected because PCR is required. ${ }^{32)}$ Typical amplicon lengths ranging between 100-300 bp are recommended. RP mutations were screened using HRM analysis. ${ }^{33,34)}$ Aguirre-Lamban et al. showed that HRM is more accurate than denaturing high-performance liquid chromatography (dHPLC) using it in $A B C A 4$ gene screening of RP. ${ }^{33)}$

\section{Multiplex Ligation-dependent Probe Amplification (MLPA)}

MLPA utilizes multiplex PCR for screening and the two halves of probestargeting the specificsequence. Auniversal primer flanks each end of the probe and a fluorescent tag is added at one end. After hybridization to the target sequence, the probes are ligated to reconstitute the full-length probe and PCR-amplified. The probes differ in length and are separated and identified using capillary electrophoresis. The amounts of ligated probe will be proportional to the target copy number. By analyzing the peak of fluorescence emission, either a duplication or deletion of the target region can be identified. ${ }^{35)}$ In particular, MLPA can detect large genomic deletions and insertion unlike microarray, dHPLC and HRM. The use of MLPA has contributed to identifying mutations in patients with $\mathrm{RP}^{36,37)}$

\section{Sequencing methods}

\section{Dideoxy DNA sequencing (Sanger sequencing)}

This enzymatic sequencing method was invented by Frederick Sanger and is simply called "Sanger sequencing." It uses chainterminating ddNTPs that are similar to their dNTP counterparts abruptly terminating DNA synthesis. Current automated sequencing platforms utilize capillary electrophoresis to make reading the sequence a highly efficient process. Dideoxy termination sequencing is the most accurate method; however, it is ineffective for determining genome-scale sequences.

Table 1. Overview of Strategies for Detecting Genetic Variations

\begin{tabular}{|c|c|c|}
\hline Approach & Advantages & Limitations \\
\hline Positional cloning & Easy to perform & $\begin{array}{l}\text { Requires large families, often identifies large loci, } \\
\text { mutation detection requires second step }\end{array}$ \\
\hline Candidate gene & $\begin{array}{l}\text { Easy to perform for several genes, does not requires mapping, } \\
\text { can directly identify the causative variant/mutation }\end{array}$ & $\begin{array}{l}\text { Relies heavily on current biological knowledge success } \\
\text { rate very low }\end{array}$ \\
\hline Microarray & $\begin{array}{l}\text { Detects all types of genetic variations } \\
\text { Simultaneous identification of millions of SNPs }\end{array}$ & $\begin{array}{l}\text { Restricted to known mutations } \\
\text { Customizable arrays are expensive }\end{array}$ \\
\hline Sanger sequencing & $\begin{array}{l}\text { Higher accuracy than NGS } \\
\text { Longer reads (approximately } 1000 \text { bp) }\end{array}$ & Higher cost, lower efficacy \\
\hline Targeted resequencing & $\begin{array}{l}\text { Cost effective for finding mutations in targeted genes, detects } \\
\text { most types of genomic variation, can directly identify the } \\
\text { causative variant/mutation }\end{array}$ & $\begin{array}{l}\text { Unable to detect noncoding variants limited resolution } \\
\text { for CNV and other structural variation, coverage varies } \\
\text { according to enrichment process }\end{array}$ \\
\hline Whole exome sequencing & $\begin{array}{l}\text { Base-pair resolution exome-wide, detects most types of } \\
\text { genomic variation, can directly identify the causative } \\
\text { variant/mutation }\end{array}$ & $\begin{array}{l}\text { Unable to detect noncoding variants, limited resolution } \\
\text { for CNVs and other structural variations, coverage varies } \\
\text { according to enrichment process, relatively expensive }\end{array}$ \\
\hline Whole genome seque & $\begin{array}{l}\text { Base-pair resolution genome-wide, detects all types of genomic } \\
\text { variation, can directly identify the causative variant/mutation }\end{array}$ & $\begin{array}{l}\text { Data analysis complex, more expensive than exome } \\
\text { sequencing }\end{array}$ \\
\hline
\end{tabular}

CNV; copy-number variations 
We performed direct Sanger sequencing of $\mathrm{RHO}$ in $302 \mathrm{RP}$ patients using a capillary DNA analyzer. One novel mutation and four known mutations in 6 probands were identified. RHO mutations are present in about 2\% of Korean RP patients. This study illustrates the continued high value of Sanger sequencing for analyzing specific target regions.

\section{Next-generation sequencing (NGS)}

NGS utilizes fundamentally different sequencing technologies that were developed after the mid-2000s. A distinct feature is that NGS does not require polyacrylamide gel electrophoresis. NGS comprises 3 steps as follows: template preparation, sequencing, and combined imaging and data analysis. Each step can be performed using different several methods, and established commercial platforms use them in various combinations. A representative workflow is described here.

1) Template preparation

Generating a nonbiased source of nucleic acids is an important starting point. Randomly fragmented small genomic DNAs are called fragment templates or mate-pair templates depending on how they are created. These templates are immobilized to a support, which providesa platform for massively parallel sequencing. In solid-phase amplification, forward or reverse primers are compactly attached to a glass slide. The templates are hybridized to the immobilized primers and form clusters for sequencing. Template DNA is clonally expanded using distinct "bridge PCR amplification."

\section{2) Sequencing}

Cyclic reversible termination is a method that involves repetitive incorporation of a nucleotide modified with a terminating group and fluorescent dye, acquiring a fluorescent image, and cleaving the dye and the terminating group. After washing the unincorporated nucleotide, the next cycle is started. ${ }^{38)}$

Single nucleotide addition (Pyrosequencing) measures the proportional release of inorganic pyrophosphate using a chemiluminescent reaction and a DNA polymerase modified to add a sing le nucleotide at a time instead of a terminating nucleotide described above ${ }^{39-41)}$ Real-time sequencing identifies newly incorporated nucleotide without halting DNA synthesis. ${ }^{42)}$

\section{3) Genome alignment and assembly}

In completing the short NGS reads, fragmented base sequences can be aligned to the known reference sequence or can be assem- bled de novo. ${ }^{43-45)}$ The alignment approach is less expensive and faster, however it is problematic when the reads are in repetitive regions or may not exist in the reference genome. ${ }^{46)}$

The most widely used platform employs solid phase amplification and cyclic reversible termination. The concordance and false-positive rates are $99.5 \%$ and $2.5 \%$, respectively, for detecting single nucleotide variants. ${ }^{47)}$ Although NGS is constantly improving in accuracy, it has never surpassed Sanger sequencing. Therefore, Sanger sequencing isstill considered the gold standard.

\section{Targeted resequencing}

Despite the advent of massively parallel sequencing techniques that enable individual laboratories to sequence a whole human genome, whole genome sequencing is still expensive. Recent studies have introduced new methods to target larger regions of the human genome, which are suited to available massively parallel sequencing techniques and are described as genome capture or genome enrichment.

Targeted resequencing has been used to identify mutations in known and novel genes that cause hereditary disorders, such as familial exudative vitreoretinopathy and recessive nonsyndromic hearing loss discovered. ${ }^{48,49)}$

\section{Unbiased sequencing approaches-Exome sequencing}

Conventional genetic research tools, such as linkage mapping or candidate gene resequencing, have identified one-third to one-half of the loci underlying Mendelian inherited disorders. ${ }^{50)}$ However, there are several limitations to conventional gene discovery strategies. These include the scarcity of available large families, patients, locus heterogeneity, and reduced penetrance.

Conventional gene discovery depends on the biased sequencing of only a part of an entire genome. NGS has enabled sequencing at very low cost compared to conventional methods and unbiased sequencing such as whole exome sequencing or whole genome sequencing. Whole exome sequencing depends on targeted capture and massively parallel sequencing. Although the exome represents approximately $1 \%$ of a whole exome, sequencing can be a successful strategy for discovering a rare allele underlying a Mendelian-inherited disease. First, positional cloning focusing on protein coding region has been effective in studying monogenic disorders ${ }_{1}^{50)}$ and most of the known causal alleles of such diseases 
are caused by mutations in protein coding regions. ${ }^{511}$ Second, most protein-altering variants, such as missense, nonsense, or indel mutations are predicted to be significant. ${ }^{52)}$ Therefore, the exome represents a concentrated core that can be exploited for identifying causal variants of genetic disorders.

The most important aspect of exome sequencing is to confirm the causal variants among numerous mutations. The section that follows explains how causal mutations can be identified.

\section{Discrete filtering}

Discrete filtering depends on the assumption that variants found in a normal population cannot be a causal allele underlying a rare hereditary disease. This method depends on publicly accessible databases of known genetic variants. There are also several limitations to discrete filtering. For example, the database may contain erroneous pathologic variants. And a rarely occurring variant in normal population can be a real pathologic allele, this situation may occur for recessive traits because of the carrier state of heterozygous recessive genotypes. ${ }^{53)}$

\section{Stratifying candidates after discrete filtering}

Candidate alleles can be stratified according to their predicted severity. For example, frameshift or stop codons can be given greater weight than missense variants. Further, candidate alleles can be stratified according to functional properties of the encoded protein. Alternatively, highly conserved sequences can provide insights. Because mutations of conserved sequence are likely to be deleterious, they can contribute to making selections.

\section{Filtering using tests of association}

Two-sample tests, which compare unrelated individuals with the same phenotype to controls, can mitigate the problems of discrete filtering or suggest an adequate sample size for overcoming complicating factors. As the documentation of the exome dataset increases in quality, the ability to detect causal alleles will improve.

\section{Pedigree information}

Pedigree information is valuable for reducing the number of candidate alleles of a Mendelian disorder. In the absence of mapping data, sequencing the most genetically unrelated individuals is helpful. If mapping data is available, the sequences of two indivi- duals whose haplotypes overlap the least are determined. In a de novo case, sequencing the DNA of parents and their offspring is an effective approach.

Defining the exome in its entirety faces some significant obstacles. First, the available exome database is not perfect. Moreover, sequencing regions other than the exome will provide useful information, such as the identity of microRNAs or promoter regions. Second, technical failure can occur due to inadequate coverage or incorrect variant calling. Either poor capturing ability or poor sequencing efficiency can cause inadequate coverage. Analytical failure is yet another problem and can originate from the limitations of discrete filtering. If an etiological allele exists in a control dataset because of reduced penetrance, false-negative calls can be made. A false-positive call that identifies a nondisease-causing allele can pass filtering in cases of segmental duplication such as a processed pseudogene.

Whole exome sequencing can be applied to the diagnosis of inherited diseases characterized by atypical manifestations or for which only incomplete laboratory criteria are available as well as to the discovery of novel mutations. For example, several studies using exome sequencing have revealed novel mutations in patients with RP. ${ }^{54-56)}$ Bowne et al. revealed novel RPE65 mutation using combination of candidate gene screening and whole-exome sequencing. ${ }^{54)}$ This was the first report of AD pattern in RPE65 mutation. Zuchner et al. identified novel causal DHDDS gene in a single, one-generation family and demonstrated the usefulness of combining whole-exome sequencing with rapid in vivo studies. Further, exome sequencing can be used to screen for carriers of rare recessive diseases. ${ }^{57)}$

\section{Closing remarks}

Whole exome or genome sequencing will be feasible in the near future because of lowering costs. One may guess that capturing the target will still be required. Despite gradual progress in sequencing technology, we should always consider limited resources and cost-effectiveness. Capture experiments allow sequencing more samples but with limited capacity. Therefore, it seems reasonable to conclude that targeted sequencing will be used along with whole-genome or whole-exome sequencing. For example, unbiased sequencing can be used for discovering the unrevealed one-half of causal genes of RP, and targeted sequencing can be adopted for practical molecular diagnosis. 


\section{References}

1. Hartong DT, Berson EL, Dryja TP. Retinitis pigmentosa. Lancet 2006;368: 1795-809.

2. Retinal Information Network website. http://www.sph.uth.tmc.edu/ retnet/

3. Daiger SP, Bowne SJ, Sullivan LS. Perspective on genes and mutations causing retinitis pigmentosa. Arch Ophthalmol 2007;125:151-8.

4. Ferrari S, Di lorio E, Barbaro V, Ponzin D, Sorrentino FS, Parmeggiani F. Retinitis pigmentosa: genes and disease mechanisms. Curr Genomics 2011;12:238-49.

5. Royer-Pokora B, Kunkel LM, Monaco AP, Goff SC, Newburger PE, Baehner RL, et al. Cloning the gene for an inherited human disorder-chronic granulomatous disease--on the basis of its chromosomal location. Nature 1986;322:32-8.

6. Blanton $\mathrm{SH}$, Heckenlively JR, Cottingham AW, Friedman J, Sadler LA,

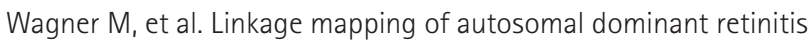
pigmentosa (RP1) to the pericentric region of human chromosome 8 . Genomics 1991;11:857-69.

7. Farrar GJ, Kenna P, Jordan SA, Kumar-Singh R, Humphries MM, Sharp $E M$, et al. A three-base-pair deletion in the peripherin-RDS gene in one form of retinitis pigmentosa. Nature 1991;354:478-80.

8. Chakarova CF, Hims MM, Bolz H, Abu-Safieh L, Patel RJ, Papaioannou $M G$, et al. Mutations in HPRP3, a third member of pre-mRNA splicing factor genes, implicated in autosomal dominant retinitis pigmentosa. Hum Mol Genet 2002;11:87-92.

9. Lander ES, Botstein D. Homozygosity mapping: a way to map human recessive traits with the DNA of inbred children. Science 1987;236: 1567-70.

10. Bandah-Rozenfeld $\mathrm{D}$, Collin RW, Banin $\mathrm{E}$, van den Born $\mathrm{LI}$, Coene $\mathrm{KL}$, Siemiatkowska AM, et al. Mutations in IMPG2, encoding interphotoreceptor matrix proteoglycan 2, cause autosomal-recessive retinitis pigmentosa. Am J Hum Genet 2010;87:199-208.

11. Bandah-Rozenfeld D, Mizrahi-Meissonnier L, Farhy C, Obolensky A, Chowers I, Pe'er J, et al. Homozygosity mapping reveals null mutations in FAM161A as a cause of autosomal-recessive retinitis pigmentosa. Am J Hum Genet 2010;87:382-91.

12. Collin RW, Safieh C, Littink KW, Shalev SA, Garzozi HJ, Rizel L, et al. Mutations in C2orf71 cause autosomal-recessive retinitis pigmentosa. Am J Hum Genet 2010;86:783-8.

13. den Hollander Al, McGee TL, Ziviello C, Banfi S, Dryja TP, GonzalezFernandez $F_{1}$ et al. A homozygous missense mutation in the IRBP gene (RBP3) associated with autosomal recessive retinitis pigmentosa. Invest Ophthalmol Vis Sci 2009;50:1864-72.

14. Dvir L, Srour G, Abu-Ras R, Miller B, Shalev SA, Ben-Yosef T. Autosomalrecessive early-onset retinitis pigmentosa caused by a mutation in $P D E 6 G$, the gene encoding the gamma subunit of rod cGMP phosphodiesterase. Am J Hum Genet 2010;87:258-64.
15. Estrada-Cuzcano A, Neveling K, Kohl S, Banin E, Rotenstreich Y, Sharon $D_{1}$ et al. Mutations in C8orf37, encoding a ciliary protein, are associated with autosomal-recessive retinal dystrophies with early macular involvement. Am J Hum Genet 2012;90:102-9.

16. Tabor HK, Risch NJ, Myers RM. Candidate-gene approaches for studying complex genetic traits: practical considerations. Nat Rev Genet 2002; 3:391-7.

17. Pullat J, Kusnezow W, Jaakson K, Beier M, Hoheisel JD, Metspalu A. Arrayed primer extension on in situ synthesized 5 '--> $^{\prime}$ ' oligonucleotides in microchannels. N Biotechnol 2008;25:133-41.

18. Shumaker JM, Metspalu A, Caskey CT. Mutation detection by solid phase primer extension. Hum Mutat 1996;7:346-54.

19. Ávila-Fernández A, Cantalapiedra D, Aller E, Vallespín E, AguirreLambán J, Blanco-Kelly F, et al. Mutation analysis of 272 Spanish families affected by autosomal recessive retinitis pigmentosa using a genotyping microarray. Mol Vis 2010;16:2550-8.

20. Audo I, Lancelot ME, Mohand-Saïd S, Antonio A, Germain A, Sahel JA et al. Novel $C 20 r f 71$ mutations account for $\sim 1 \%$ of cases in a large French arRP cohort. Hum Mutat 2011;32:E2091-103.

21. Jaijo T, Aller E, Garcia-Garcia G, Aparisi MJ, Bernal S, Avila-Fernández A, et al. Microarray-based mutation analysis of 183 Spanish families with Usher syndrome. Invest Ophthalmol Vis Sci 2010;51:1311-7.

22. Schaaf CP, Wiszniewska J, Beaudet AL. Copy number and SNP arrays in clinical diagnostics. Annu Rev Genomics Hum Genet 2011;12:25-51.

23. LaFramboise T. Single nucleotide polymorphism arrays: a decade of biological, computational and technological advances. Nucleic Acids Res 2009;37:4181-93.

24. Kim C, Kim KJ, Bok J, Lee EJ, Kim DJ, Oh JH, et al. Microarray-based mutation detection and phenotypic characterization in Korean patients with retinitis pigmentosa. Mol Vis 2012;18:2398-410.

25. Ostergaard $E_{1}$ Duno $M$, Batbayli M, Vilhelmsen $K_{1}$ Rosenberg T. A novel MERTK deletion is a common founder mutation in the Faroe Islands and is responsible for a high proportion of retinitis pigmentosa cases. Mol Vis 2011;17:1485-92.

26. González-del Pozo M, Borrego S, Barragán I, Pieras JI, Santoyo J, Matamala $\mathrm{N}$, et al. Mutation screening of multiple genes in Spanish patients with autosomal recessive retinitis pigmentosa by targeted resequencing. PLoS One 2011;6:e27894.

27. Kannabiran $\mathrm{C}$, Singh $\mathrm{H}$, Sahini N, Jalali S, Mohan G. Mutations in TULP1, NR2E3, and MFRP genes in Indian families with autosomal recessive retinitis pigmentosa. Mol Vis 2012;18:1165-74.

28. Siemiatkowska AM, Arimadyo K, Moruz LM, Astuti GD, de CastroMiro M, Zonneveld MN, et al. Molecular genetic analysis of retinitis pigmentosa in Indonesia using genome-wide homozygosity mapping. Mol Vis 2011;17:3013-24.

29. Blanco-Kelly F, Garcia-Hoyos $M_{1}$ Cortón $M_{1}$ Avila-Fernández $A$, RiveiroÁlvarez R, Giménez $A$, et al. Genotyping microarray: mutation screening in Spanish families with autosomal dominant retinitis pigmentosa. Mol Vis 2012;18:1478-83. 
30. Erali $\mathrm{M}$, Wittwer $\mathrm{CT}$. High resolution melting analysis for gene scanning. Methods 2010;50:250-61.

31. Reed GH, Kent JO, Wittwer CT. High-resolution DNA melting analysis for simple and efficient molecular diagnostics. Pharmacogenomics 2007:8:597-608.

32. De Leeneer K, Coene I, Poppe B, De Paepe A, Claes K. Rapid and sensitive detection of $B R C A 1 / 2$ mutations in a diagnostic setting: comparison of two high-resolution melting platforms. Clin Chem 2008;54:982-9.

33. Aguirre-Lamban J, Riveiro-Alvarez R, Garcia-Hoyos M, Cantalapiedra

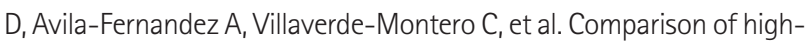
resolution melting analysis with denaturing high-performance liquid chromatography for mutation scanning in the ABCA4 gene. Invest Ophthalmol Vis Sci 2010;51:2615-9.

34. Sergouniotis PI, Li Z, Mackay DS, Wright GA, Borman AD, Devery SR, et al. A survey of DNA variation of $C 20 r f 71$ in probands with progressive autosomal recessive retinal degeneration and controls. Invest Ophthalmol Vis Sci 2011;52:1880-6.

35. Sellner LN, Taylor GR. MLPA and MAPH: new techniques for detection of gene deletions. Hum Mutat 2004;23:413-9.

36. Rose AM, Mukhopadhyay R, Webster AR, Bhattacharya SS, Waseem $\mathrm{NH}$. A $112 \mathrm{~kb}$ deletion in chromosome $19 \mathrm{q} 13.42$ leads to retinitis pigmentosa. Invest Ophthalmol Vis Sci 2011;52:6597-603.

37. Aller E, Jaijo T, Garcia-Garcia G, Aparisi MJ, Blesa D, Diaz-Llopis M, et al. Identification of large rearrangements of the $P C D H 15$ gene by combined MLPA and a CGH: large duplications are responsible for Usher syndrome. Invest Ophthalmol Vis Sci 2010;51:5480-5.

38. Metzker ML. Emerging technologies in DNA sequencing. Genome Res 2005;15:1767-76.

39. Margulies $M$, Egholm M, Altman WE, Attiya S, Bader JS, Bemben LA, et al. Genome sequencing in microfabricated high-density picolitre reactors. Nature 2005;437:376-80.

40. Ronaghi $M$, Karamohamed $S$, Pettersson $B$, Uhlén $M$, Nyrén P. Realtime DNA sequencing using detection of pyrophosphate release. Anal Biochem 1996;242:84-9.

41. Ronaghi $M$, Uhlén $M$, Nyrén P. A sequencing method based on realtime pyrophosphate. Science 1998;281:363, 365.

42. Metzker ML. Sequencing in real time. Nat Biotechnol 2009;27:150-1.

43. Pop M, Salzberg SL. Bioinformatics challenges of new sequencing technology. Trends Genet 2008;24:142-9.

44. Chaisson MJ, Brinza D, Pevzner PA. De novo fragment assembly with short mate-paired reads: Does the read length matter? Genome Res 2009;19:336-46.
45. Trapnell C, Salzberg SL. How to map billions of short reads onto genomes. Nat Biotechnol 2009;27:455-7.

46. Frazer KA, Murray SS, Schork NJ, Topol EJ. Human genetic variation and its contribution to complex traits. Nat Rev Genet 2009;10:241-51.

47. Bentley DR, Balasubramanian S, Swerdlow HP, Smith GP, Milton J, Brown $C G$, et al. Accurate whole human genome sequencing using reversible terminator chemistry. Nature 2008;456:53-9.

48. Nikopoulos K, Gilissen C, Hoischen A, van Nouhuys CE, Boonstra FN, Blokland $E A$, et al. Next-generation sequencing of a $40 \mathrm{Mb}$ linkage interval reveals TSPAN12 mutations in patients with familial exudative vitreoretinopathy. Am J Hum Genet 2010;86:240-7.

49. Rehman AU, Morell RJ, Belyantseva IA, Khan SY, Boger ET, Shahzad $M$, et al. Targeted capture and next-generation sequencing identifies C9orf75, encoding taperin, as the mutated gene in nonsyndromic deafness DFNB79. Am J Hum Genet 2010;86:378-88.

50. Antonarakis SE, Beckmann JS. Mendelian disorders deserve more attention. Nat Rev Genet 2006;7:277-82.

51. Stenson PD, Ball EV, Howells K, Phillips AD, Mort M, Cooper DN. The Human Gene Mutation Database: providing a comprehensive central mutation database for molecular diagnostics and personalized genomics. Hum Genomics 2009:4:69-72.

52. Kryukov GV, Pennacchio LA, Sunyaev SR. Most rare missense alleles are deleterious in humans: implications for complex disease and association studies. Am J Hum Genet 2007;80:727-39.

53. Ng SB, Buckingham KJ, Lee C, Bigham AW, Tabor HK, Dent KM, et al. Exome sequencing identifies the cause of a mendelian disorder. Nat Genet 2010;42:30-5.

54. Bowne SJ, Humphries MM, Sullivan LS, Kenna PF, Tam LC, Kiang AS, et al. A dominant mutation in RPE65 identified by whole-exome sequencing causes retinitis pigmentosa with choroidal involvement. Eur J Hum Genet 2011;19:1074-81.

55. Khateb S, Zelinger L, Ben-Yosef T, Merin S, Crystal-Shalit O, Gross M, et al. Exome sequencing identifies a founder frameshift mutation in an alternative exon of USH1C as the cause of autosomal recessive retinitis pigmentosa with late-onset hearing loss. PLoS One 2012;7:e51566.

56. Züchner S, Dallman J, Wen R, Beecham G, Naj A, Farooq A, et al. Wholeexome sequencing links a variant in DHDDS to retinitis pigmentosa. Am J Hum Genet 2011;88:201-6.

57. Bell CJ, Dinwiddie DL, Miller NA, Hateley SL, Ganusova EE, Mudge J, et al. Carrier testing for severe childhood recessive diseases by nextgeneration sequencing. Sci Transl Med 2011;3:65ra4. 